\title{
Expression of Wnt pathway components frizzled and disheveled in colon cancer arising in patients with inflammatory bowel disease
}

\author{
X. JOANN YOU ${ }^{1,2}$, PETER J. BRYANT ${ }^{2}$, FRANCES JURNAK ${ }^{3}$ and RANDALL F. HOLCOMBE ${ }^{1}$ \\ ${ }^{1}$ Division of Hematology/Oncology and Chao Family Comprehensive Cancer Center; Departments of \\ ${ }^{2}$ Developmental and Cell Biology, ${ }^{3}$ Physiology and Biophysics, University of California, Irvine, CA, USA
}

Received November 30, 2006; Accepted January 18, 2007

\begin{abstract}
Mutations in apc which lead to activation of the Wnt signaling pathway are a hallmark of sporadic colon cancers but occur infrequently in colon cancers arising in patients with inflammatory bowel disease (IBD). There is evidence, however, that other components of the Wnt pathway may be altered in IBD-related colon cancer. In this study, we examined the expression the Wnt pathway components frizzled $(\mathrm{Fz})$, the cell surface receptor, and disheveled (DVL), a family of cytoplasmic signal transduction molecules, in IBD and IBDrelated colon cancer. Paraffin sections of normal and malignant colon tissues were obtained from patients with a history of ulcerative colitis and from controls with sporadic colon cancer. Tissue sections were stained with antibodies directed against Fz1/2 receptors and DVL1, DVL2 and DVL3 and antigen expression visualized by immunohistochemistry. Fz1/2 receptors were minimally expressed in normal IBD mucosa, were not expressed in IBD colon cancer, but exhibited strong expression in dysplastic tissues adjacent to the cancers. DVL1 was not expressed in IBD normal mucosa or normal mucosa from non-IBD patients, but was expressed in all cancers. DVL2 and DVL3 were expressed in all normal mucosa samples tested, and in sporadic colon cancer, but were not expressed in colon cancers arising in IBD patients. The characteristics of $\mathrm{Fz}$ and DVL expression in IBD tissues reported herein provides evidence of the importance of Wnt signaling in IBD and IBD-related colon cancer and, specifically, the significance of non-APC components of this pathway. Fz may serve as a marker for dyspasia in IBD patients and DVL1 is a potential therapeutic target for IBD-related colon cancer.
\end{abstract}

Correspondence to: Dr Randall F. Holcombe, University of California, Irvine Medical Center, 101 The City Drive, Bld. 56, Room 247, Orange, CA 92868, USA

E-mail: rholcomb@uci.edu

Key words: Wnt signaling, frizzled receptor, colon cancer, disheveled, inflammatory bowel disease

\section{Introduction}

Activation of the Wnt signaling pathway is of paramount importance in the development of sporadic colon cancer. Sporadic colon cancers $(>80 \%)$ are associated with mutations in the apc gene $(1,2)$. This leads to the accumulation of cytoplasmic and nuclear B-catenin, and upregulation of LEF/TCFdependent transcription of growth promoting genes such as cyclinD1 and c-myc $(3,4)$. While mutations in apc which result in the stabilization of $B$-catenin are extremely common in sporadic colon cancer, such mutations appear to be rare in tumors from patients with ulcerative colitis (UC) (5-7). UCassociated rat colon carcinogenesis induced by 1-hydroxyanthraquinone and methylazoxymethanol acetate does not involve apc mutations $(8,9)$. However, $\beta$-catenin mutations are seen in rat colon cancer induced by these agents, strongly implicating Wnt signaling in these tumors (10). Abnormal $\beta$-catenin protein expression may be more closely linked to E-cadherin alterations in UC-related cancers than to the APC abnormalities seen in sporadic cancers (11). Analysis of sporadic and inflammatory bowel disease (IBD)-related cancers reveals similar patterns of expression of p53 and $\beta$-catenin, suggesting similar pathways of carcinogenesis (12). Correspondingly, molecular alterations in UC-associated and sporadic hyperplastic polyps are genotypically similar (13). These studies support the hypothesis that Wnt signaling is a critical contributor to the pathogenesis of UC/IBD-related colon cancers, but suggests that alterations in Wnt signal pathway components are separate and distinct from the apc mutations commonly observed in sporadic colon cancer. Nucleotide array comparison of inflamed intestinal mucosa of patients with UC and Chron's disease revealed increased expression of three Wnt pathway genes, Sarpl, frizzled $(F z)$ and disheveled $(D V L)$ in samples from patients at highest risk for colon cancer, those with longstanding UC (14).

Increased expression of Fz1/2 receptors has been described in sporadic colon cancer (15). The expression appears to be primarily in poorly differentiated tumors and concentrated at the invasion margin. The overexpression may be linked to Wnt pathway activation at the invasion margin (16) and may be a marker for tumor invasiveness. Increased expression of DVL1 has been reported in primary breast cancers (17) and cervical squamous cell carcinomas (18). While no specific association 


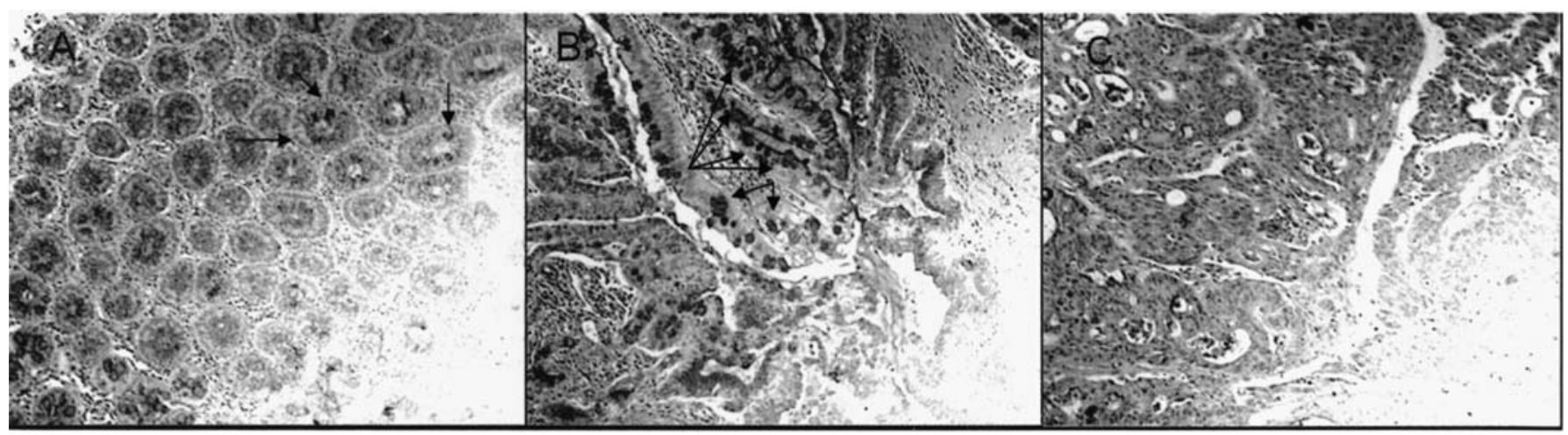

Figure 1. Frizzled 1/2 expression by immunohistochemistry in representative tissue samples from patients with inflammatory bowel disease and colon cancer. A, depicts normal (IBD) colonic mucosa. B, depicts an area of dysplasia and hyperproliferation adjacent to the colon cancer. C, depicts colon cancer. Weak expression of Fz1/2 is observed in normal mucosa with strong expression in the dysplastic area (arrows). No expression is seen in the cancer tissue.

between DVL2 and human cancer has been reported, DVL3 is overexpressed in non-small cell lung cancers (NSCLC), and inhibition of DVL activity by small inhibitory RNA (siRNA) molecules in vitro results in growth inhibition of a NSCLC cell line (19). DVL is also overexpressed in human mesothelioma (20). These data, along with the evidence that nonAPC-related Wnt pathway activation is involved in colon carcinogenesis in the setting of UC, led to this study of Fz and DVL expression in IBD-associated colon cancer.

\section{Materials and methods}

Tissue acquisition. Tissue samples were obtained from archived specimens at the University of California, Irvine Medical Center and through the Cooperative Human Tissue Network at Vanderbilt University which is supported by the National Cancer Institute. All tissue was obtained under local IRB approval and was stripped of all patient identifiers. Paraffin-embedded tissue sections of colon cancer and normal colonic mucosa were obtained from patients with sporadic colon cancer and patients with colon cancer and a history of inflammatory bowel disease (in these cases, all with a history of ulcerative colitis).

Immunohistochemistry. Tissue sections from paraffinembedded samples were deparaffinized with xylene/ethanol and incubated with primary antibody $(1-5 \mu \mathrm{g} / \mathrm{ml})$ overnight at $4^{\circ} \mathrm{C}$. Primary antibodies included polyclonal goat antihuman Fz1+2 antibodies, which react with both human Fz1 and Fz2 cell surface receptors (clone sc-7429, Santa Cruz Biotechnology, Santa Cruz, CA) and antibodies specific for DVL1 (clone Ab5970, rabbit polyclonal, Chemicon Corp, Temecula, CA), DVL2 (clone sc-7399, goat polyclonal, Santa Cruz Biotechnology) and DVL 3 (clone sc-26504, goat polyclonal, Santa Cruz Biotechnology). Following primary antibody incubation, tissue sections were washed with PBS containing $0.3 \%$ Triton-X-100, incubated with biotinylated donkey anti-goat or anti-rabbit secondary antibody $(1 \mu \mathrm{g} / \mathrm{ml})$ and then subsequently with horseradish peroxidase and DAB chromogen. Donkey serum (8\%) was utilized as a blocking agent to reduce background staining. Antigen retrieval was accomplished by boiling tissue slides for 5-10 min in $10 \mathrm{mM}$ sodium citrate, $\mathrm{pH}$ 6.0. Endogenous peroxidase activity was blocked by incubating with $3 \% \mathrm{H}_{2} \mathrm{O}_{2} / \mathrm{ddH}_{2} \mathrm{O}$ for $10 \mathrm{~min}$. The tissue slides were visualized with an Olympus microscope system utilizing Narmoski Optics and recorded separately as digital images at multiple magnifications ranging from $\mathrm{x} 100$ to $\mathrm{x} 1000$.

\section{Results}

Frizzled receptors $1 / 2$ were minimally expressed in normal colonic mucosa derived from patients with inflammatory bowel disease (Fig. 1). No expression was seen in IBD-derived colon cancers, regardless of histology (moderately, well differentiated or poorly differentiated). No expression was seen at the invasion margin for any of the 12 IBD cancers studied. However, significant expression was seen in areas characterized by dysplasia which were adjacent to a majority of the IBD tumors analyzed.

DVL1 was not expressed in normal mucosa from patients with IBD or patients who presented with sporadic colon cancer. DVL2 and DVL3 were expressed in the normal mucosa of both groups. In cancer specimens, DVL1 was uniformly expressed in both IBD patients and sporadic colon cancer patients even though no DVL1 expression was seen in the normal tissue from the same patients. In cancer specimens from the non-IBD patients, those with sporadic colon cancer, DVL2 and DVL3 were both expressed. However, neither DVL2 nor DVL3 were expressed in colon cancers in IBD patients (Fig. 2 and Table I). Areas of dysplasia adjacent to IBD-associated colon cancers had an expression pattern of DVL1, DVL2 and DVL3 which was similar to that seen in normal IBD mucosa.

\section{Discussion}

Colon carcinogenesis involves a series of sequential genetic changes as well as epigenetic changes in the expression of components of various signaling pathways. Wnt:Fz interactions at the cell surface (and possibly the activity of other upstream components of the pathway) are critical for regulating Wnt signal throughput, even in tumors which harbor activating mutations in apc $(21,22)$. These interactions, which typically 


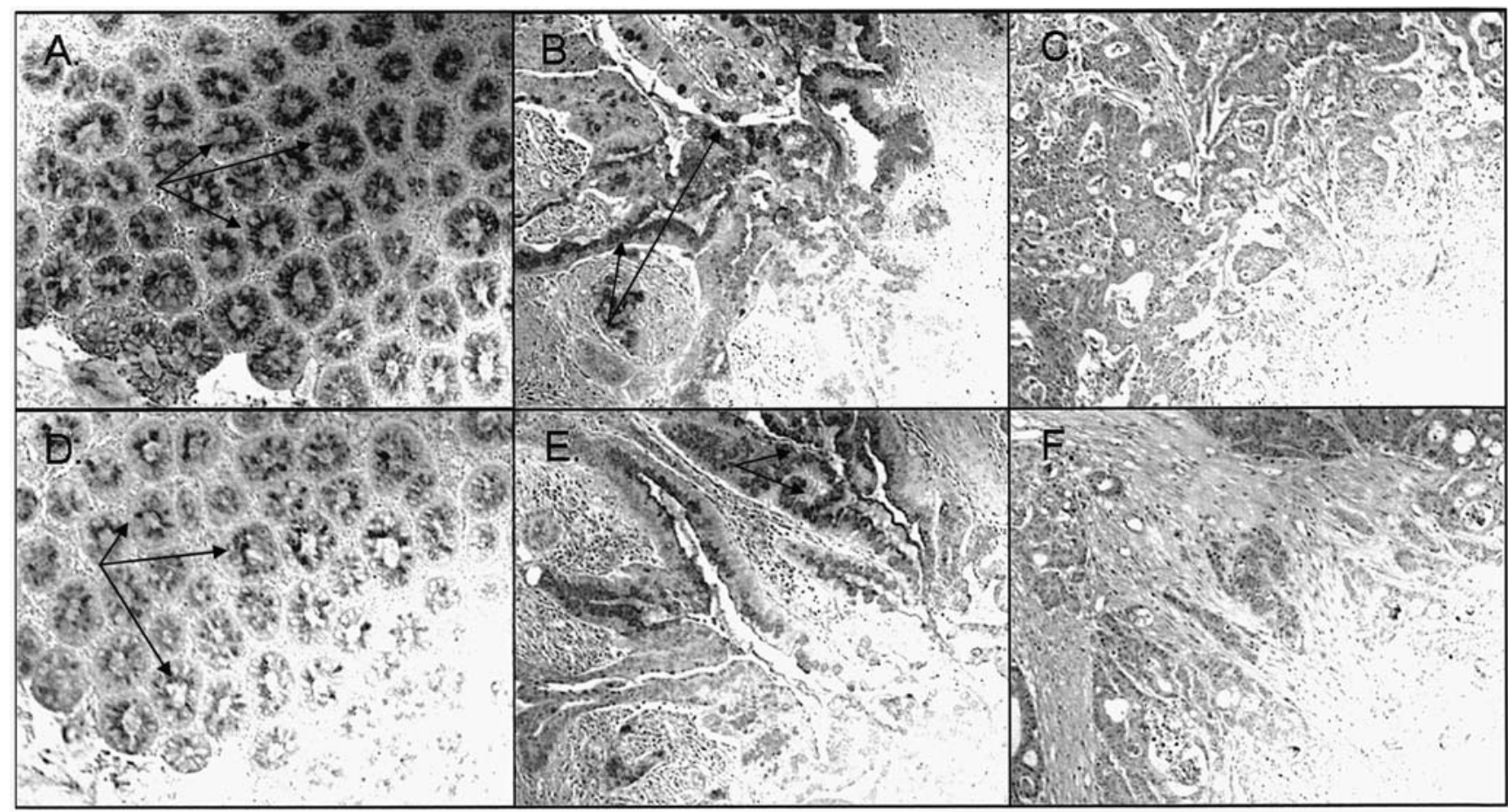

Figure 2. DVL2 (A-C) and DVL3 (D-F) expression by immunohistochemistry in representative tissue samples from patients with inflammatory bowel disease and colon cancer. Expression of DVL2 and DVL3 is seen in the normal (IBD) colonic mucosa (A and D, arrows) and dysplastic areas adjacent to the colon cancer (B and E, arrows). No expression is seen in colon cancer tissue (C and F).

Table I. Expression of DVL1, DVL2 and DVL3 in normal mucosa from patients with IBD and from patients with no history of colitis, and in IBD-related colon cancers and sporadic colon cancers.

\begin{tabular}{lrccc}
\hline & N & DVL1 & DVL2 & DVL3 \\
\hline IBD normal mucosa & 6 & $(-)$ & $(+)$ & $(+)$ \\
IBD cancer & 12 & $(+)$ & $(-)$ & $(-)$ \\
Sporadic normal mucosa & 8 & $(-)$ & $(+)$ & $(+)$ \\
Sporadic cancer & 8 & $(+)$ & $(+)$ & $(+)$ \\
\hline
\end{tabular}

result in a canonical Wnt signal, promote tumor growth and progression (23) and may be involved in tumor invasion (15). Increased expression of $\mathrm{Fz}$ in inflamed mucosa from patients with longstanding UC suggests that signaling through this receptor may be involved in pre-malignant changes and malignant transformation in patients with IBD. In this study, we demonstrate that Fz1/2 is overexpressed in dysplastic mucosa adjacent to IBD-associated cancers, while expressed only weakly in normal IBD mucosa and not expressed in the cancer tissue itself. Fz1/2 may facilitate increased Wnt signaling in pre-malignant dysplastic tissue, promoting cell growth and proliferation. As such, it may be a useful marker as an aid in identifying dysplasia in patients with IBD. In overt cancer, activation of Wnt and other signaling pathways due to genetic mutations may be sufficient to obviate the need for additional stimulation via $\mathrm{Wnt}: \mathrm{Fz}$ interactions.

A prior study described the expression of DVL3 in normal and malignant colon tissue (24) and our data support these prior findings. However, in examining the expression of each of the family members, the expression of the three DVL proteins is distinct, with DVL1 not expressed in normal IBDand non-IBD mucosa, but expressed in all cancers. DVL2 and DVL3, on the contrary, are expressed in normal mucosa from each source, and are expressed in sporadic colon cancer, but are not expressed in IBD-associated colon cancer. The amino acid sequence and putative structure indicate that there are significant differences between DVL1 and DVL2/DVL3. These may equate to functional differences relevant to their unique distribution of expression.

The region between DVL1 amino acid 475 and DVL1 amino acid 633 differs considerably among the three proteins. This region is probably made up of flexible coils and could be a binding region which is only structured in the presence of its ligand/binding partner. These differences between the DVL family members may affect the binding affinity of various substrates which, in turn, may affect function. At least 17 proteins have been defined as binding partners of DVL family members affecting processes such as kinase and phosphatase activity, ß-catenin-dependent Wnt signaling, PCP-CE (tissue polarity/convergence-extension) signaling, notch signaling and $ß$-arrestin activity (25).

The N-terminal region of DVL1 (amino acids 1 through 474) contains a PDZ domain and a DEP domain. The PDZ domain of Xenopus disheveled binds a protein called Dapper which is an antagonist of B-catenin and JNK signaling. The three amino acids immediately preceding the Dapper binding region are different in DVL1 when compared to DVL2 and DVL3 which could affect putative Dapper-DVL interactions and signify another functional difference between the DVL family members (26). 
The DEP domain has three functional regions. One is a putative membrane localization region where 7 positively charged amino acids cluster together. DVL1 contains all 7 but DVL2 and DVL3 share only 5 of these amino acids. Another region in DEP is Helix 1, which provides key interactions between Xdsh and domains of other proteins involved in Xenopus axis induction. Only DVL1 shares significant sequence identity with this region of Xenopus disheveled. The sequences of DVL2 and DVL3 are considerably different in this helix (27).

Overall, the expression of specific DVL family members in non-malignant and cancerous tissues appears very specific. Unlike sporadic colon cancers, IBD-associated colon cancers express only one DVL family member, DVL1. Thus, DVL1 may be a unique therapeutic target for this group of patients. In sporadic colon cancer, redundant functionality between DVL1 and DVL2/DVL3 may make such a therapeutic approach less effective.

The characteristics of $\mathrm{Fz}$ and DVL expression in IBD tissues reported herein provides further evidence of the importance of Wnt signaling in IBD and IBD-related colon cancer and, specifically, the significance of non-APC components of this pathway.

\section{Acknowledgements}

This study was supported by NIH grant DK65642 and a grant from the Broad Medical Research Foundation (IBD-0065R). Some tissue samples were obtained with the assistance of the NCI-supported Cooperative Human Tissue Network based at Vanderbilt University.

\section{References}

1. Miyoshi Y, Nagase H, Ando H, Ichii S, Nakatsura S, Aoki T, Miki Y, Mori T and Nakamura Y: Somatic mutations of the APC gene in colorectal tumors: Mutation cluster region in the APC gene. Hum Mol Genet 1: 229-233, 1992.

2. Potter JD: Colorectal Cancer: Molecules and populations. J Natl Cancer Inst 91: 916-932, 1999.

3. He TC, Sparks AB, Rago C, Hermeking H, Zawel L, da Costa LT, Morin PJ, Vogelstein B and Kinzler KW: Identification of c-MYC as a target of the APC pathway. Science 281: 1509-1512, 1998.

4. Testu O and McCormick F: Beta-catenin regulates expression of cyclin D1 in colon carcinoma cells. Nature 398: 422-426, 1999.

5. Aust DE, Terdiman JP, Willenbucher RF, Molinaro-Clark A, Chang CG, Baretton GB, Loehrs U and Waldman FM: The APC/beta-catenin pathway in ulcerative colitis-related colorectal carcinomas: A mutational analysis. Cancer 94: 1421-1427, 2002.

6. Umetani N, Sasaki S, Watanabe T, Shinozaki M, Matsuda K, Ishigami H, Ueda E and Muto T: Genetic alterations in ulcerative colitis-associated neoplasia focusing on APC, K-ras gene and microsatellite instability. Jpn J Cancer Res 90: 1081-1087, 1999.

7. Tarmin L, Yin J, Harpaz N, Kozam M, Noordzij J, Antonio LB, Jiang HY, Chan O, Cymes K and Meltzer SJ: Adenomatous polyposis coli gene mutations in ulcerative colitis-associated dysplasias and cancers versus sporadic colon neoplasms. Cancer Res 55: 2035-2038, 1995.

8. Tanaka T, Kohno H, Murakami M, Shimada R and Kagami S: Colitis-related rat colon carcinogenesis induced by 1-hydrozyantraquinone and methylazoxymethanol acetate. Oncol Rep 7: 501-508, 2000.

9. Suzui M, Ushijima T, Yoshimi N, Nakagama H, Hara A, Sugimura T, Nagao M and Mori H: No involvement of APC gene mutations in ulcerative colitis-associated rat colon carcinogenesis induced by 1-hydrozyanthraquinone and methylazixymethanol acetate. Mol Carcinog 20: 389-393, 1997.
10. Suzui M, Ushijima T, Dashwood RH, Yoshimi N, Sugimura T, Mori $\mathrm{H}$ and Nagao M: Frequent mutations of the rat betacatenin gene in colon cancers induced by methylazoxymethanol acetate plus 1-hydrozyanthraquinone. Mol Carcinog 24: 232-237, 1999.

11. Aust DE, Terdiman JP, Willenbucher RF, Chew K, Ferrell L, Florendo C, Molinaro-Clark A, Baretton GB, Lohrs U and Waldman FM: Altered distribution of beta-catenin, and its binding proteins E-cadherin and APC, in ulcerative colitisrelated colorectal cancers. Mol Pathol 14: 29-39, 2001.

12. Walsh SV, Loda M, Torres CM, Antonioli D and Odze RD: P53 and beta catenin expression in chronic ulcerative colitisassociated polypoid dysplasia and sporadic adenomas: an immunohistochemical study. Am J Surg Pathol 23: 963-969, 1999.

13. Odze RD, Brien T, Brown CA, Hartman CJ, Wellman A and Fogt F: Molecular alterations in chronic ulcerative colitisassociated and sporadic hyperplastic polyps: A comparative analysis. Am J Gastroenterol 97: 1235-1242, 2002.

14. Uthoff SM, Eichenberger MR, Lewis RK, Fox MP, Hamilton CJ, McAuliffe TL, Grimes HL and Falandiuk S: Identification of candidate genes in ulcerative colitis and Crohn's disease using cDNA array technology. Int J Oncol 19: 803-810, 2001.

15. Holcombe RF, Marsh JL, Waterman ML, Lin F, Milovanovic T and Truong T: Expression of Wnt ligands and frizzled receptors in colonic mucosa and in colon carcinoma. Mol Pathol 55: 220-226, 2002.

16. Brabletz T, Jung A, Hermann K, Gunther K, Hohenberger W and Kirchner T: Nuclear overexpression of the oncoprotein B-catenin in colorectal cancer is localized predominantly at the invasion front. Pathol Res Pract 194: 701-704, 1998.

17. Nagahata T, Shimada T, Harada A, Nagai H, Onda M, Yokoyama S, Shiba T, Jin E, Kawanami O and Emi M: Amplification, up-regulation and over-expression of DVL-1, the human counterpart of the Drosophila disheveled gene, in primary breast cancers. Cancer Sci 94: 515-518, 2003

18. Okino K, Nagai H, Hatta M, Nagahata T, Yoneyama K, Ohta Y, Jin E, Kawanami O, Araki T and Emi M: Up-regulation and overproduction of DVL-1, the human counterpart of the Drosophila disheveled gene, in cervical squamous cell carcinoma. Oncol Rep 10: 1219-1223, 2003.

19. Uematsu K, He B, You L, Xu Z, McCormick F and Jablons DM: Activation of the Wnt pathway in non small cell lung cancer: Evidence of disheveled overexpression. Oncogene 22: 7218-7221, 2003.

20. Uematsu K, Kanazawa S, You L, He B, Xu Z, Li K, Peterlin BM, McCormick F and Jablons DM: Wnt pathway activation in mesothelioma: Evidence of Dishevelled overexpression and transcriptional activity of beta-catenin. Cancer Res 63: 4547-4551, 2003.

21. He B, Reguart N, You L, Mazieres J, Xu Z, Lee AY, Mikami I, McCormick F and Jablons DM: Blockade of Wnt-1 signaling induces apoptosis in human colorectal cancer cells containing downstream mutations. Oncogene 24: 3054-3058, 2005.

22. Suzuki H, Gabrielson E, Chen W, van Engeland M, Anbazhagan R, Weijenberg MP, Herman JG and Baylin SB: Epigenetic inactivation of SFRP genes allows constitutive WNT signaling in colorectal cancer. Nat Genet 31: 141-149, 2002.

23. Vincan E: Frizzled/Wnt signaling: The insidious promoter of tumour growth and progression. Front Biosci 9: 1023-1034, 2004.

24. Bui TD, Beier DR, Jonssen M, Smith K, Dorrington SM, Kaklamanis L, Kearney L, Regan R, Sussman DJ and Harris AL: cDNA cloninc of a human disheveled DVL-3 gene, mapping to 3 q27, and expression in human breast and colon carcinomas. Biochem Biophys Res Commun 239: 510-516, 1997.

25. Wharton KA: Runnin' with the DVL: Proteins that associate with Dsh/Dvl and their significance to Wnt signal transduction. Dev Biol 253: 1-17, 2003.

26. Cheyette BN, Waxman JS, Miller JR, Takemaru K, Sheldahl LC, Khlebtsova N, Fox EP, Earnest T and Moon RT: Dapper, a Dishevelled-associated antoagonist of beta-catenin and JNK signaling, is required for notochord formation. Dev Cell 2: 449-461, 2002.

27. Wong HC, Mao J, Nguyen JT, Srinivas S, Zhang W, Liu B, Li L, $\mathrm{Wu} \mathrm{D}$ and Zheng J: Structural basis of the recognition of the disheveled DEP domain in the Wnt signaling pathway. Nat Struct Biol 7: 1178-1184, 2000. 